\title{
Cooking Video Development and Everyday Cultural Politics in China
}

\author{
Bilu Guan
}

\author{
${ }^{1}$ Bilu Guan, School of Journalism and Communication, Nanjing Normal University, 210024 Nanjing, China. \\ ${ }^{*}$ Corresponding author.Email: 160201001@njnu.edu.cn
}

\begin{abstract}
One of the most popular online chefs in China, Wang Gang, has been an iconic figure in the digitization of Chinese cooking. He was called a "hardcore chef" because he showed the entire process of cooking from the very beginning (raw meat or a live duck) to the prepared dish with no fancy presentation, no embellishment and no filters. This paper explores why Wang's down-to-earth style became immensely popular on Chinese social media in recent years. Using food videos as a lens, the paper will also discuss food attitudes and the broader social and cultural factors behind food videos' development. The preference change in food videos reflects a critical reaction to China's worship of luxury banquets and the rise of grassroots cultural power. The controversy surrounding Wang Gang's cooking video, on some level, is a reflection of the conflict between these two cultures and their representative groups of people. Rather than the one-sided impact of cultural politics on cooking videos, the paper also explores how the meta-process of food/cooking (mediafication of food) constitutes society: Cooking videos influence people's ideas about food and even serve as emotional comfort_-people comment that they feel relaxed after watching Wang's videos even if they don't actually learn any cooking tips.
\end{abstract}

Keywords: Cooking videos, Wang Gang, food industry, cultural politics

\section{INTRODUCTION}

Food and cooking videos are neglected areas for culture-related studies, and health communication scholars prefer to link food communication with health literacy and promotion. Considering food is a delicate, complicated and universal material that incorporates numerous elements, food video producers on social media have abundant resources with which to develop diverse stories. Thus, food/cooking videos have been some of the hottest and most-viewed content on many platforms.

Using the cooking videos of Chef Wang (a top influencer in China) as a case study, this article explores the causes and influences of the food video trend on social media. The following research questions were formulated:

RQ1: How did the style of Wang's videos develop, from the lens of the short history of Chinese food videos?

RQ2: What are the main factors behind the popularity of Wang's videos?
RQ3: What triggered the controversy in Wang's videos, and how can it be understood from a culturalpolitical perspective?

\section{THE HISTORY OF COOKING VIDEOS IN CHINA: FROM THE "BEAUTIFUL COOKING WOMAN" TO THE "GLORIFICATION OF THE FOOD"}

In the past decades, cooking videos in China experienced a developing and evolving process. The oldest-style cooking videos in China are television cooking shows from the 2000s to the early-2010s dubbed "Beauty's Homemade Cuisine," which always highlight a pretty, nicely dressed woman in the kitchen. These videos started the trend of ex-models or -stars becoming celebrity chefs on television. An important consequence of the celebrification of the culinary field is that it overlaps with the fields of politics, fashion, popular entertainment, marketing and tourism, to name but a few, moving away from culinary traditions to lifestyle attributes. (Stringfellow, MacLaren, Maclean, \& O’Gorman, 2013)[1] Also, the emergence of female 
cooking celebrities in the old-style television cooking tutorial videos came from the women's special relationship with food - they are the main cook, deciders and purchases of the food in the family, but play a peripheral role in family talks or discussions during meals. In some rural areas in China even today, the custom that women sit alone at a different table with men, or men eat first and women eat second still exists. Females were often excluded from public banquets in terms of participation in social diet activities (Tian, Tian, Dandan, \& Wang, 2018)[2]. Given that Chinese traditional family party had various dishes, normally more than three that took time to cook, it was quite common for the female to continue to cook and stay in the kitchen during the party, even when the other family members were having the meal. During the social events and banquets, female guests were supposed to help serve the other male guests, e.g. pour the wine or order the food when necessary. Considering women were more familiar with food and cooking but were far away from social diet activities because of their lower status in socioethical relationships, the female cooking stars in the videos are not necessarily professional chefs but are supposed to fit the public ideal of a "beautiful cooking $\mathrm{mom} /$ wife (but only talk about cooking/stay in the kitchen)"

The television show "Beauty's Private Kitchen," originally produced by Phoenix Television, is a prominent example and also the last video of this type to receive nation-wide popularity. The cooking host, Shen Xin, was cited as the "No. 1 beauty anchorwoman;" however, the cuisines were relatively tedious and simple, as the show did not make the food the "selling point." The slogan for the show was "creating a new food aesthetics by combining beauty in female and food," which echoed the well-known philosophy of Gaozi, a Chinese philosopher during the Warring States period, that "the desire for food and sex is nature." Although the host does not show the sexy side of her explicitly (e.g. flashy makeup or revealing clothes), she often expressed the idea that "cooking food for a man can help to win his affections". This nicely dressing, caring women playing cooking roles more accords with the image of a "sexy women" in Chinese traditional culture, which emphasizes the reserved beauty of a female.

In the middle of the 2010s, the "Beauty's Cuisine" cooking videos on television were replaced by the growing number of cooking and food videos that popped up on social media. The focus of these social media videos moved away from the "beautiful cooking woman" to the "glorification of the food." Although the formats and contents of the videos differ in thousands of ways, the consistent feature is that the food is the absolute protagonist and must be cooked and presented beautifully, while the role of "who made the food" is played down. The videos are the reflection of the "food porn" culture on social media, but taking them further, their popularity shows the development of the social and cultural environment in China. Given the fact the average age for Chinese social media users is approximately 30 -years old, the main target population for the videos is the younger generation. This population was mostly born in the years under the China's OneChild policy, which means their family size was much smaller than their parents' generation and therefore, the traditional big family parties can only happen during holiday. Also, in the course of urbanization, a large portion of the younger generation has moved to cities. They accepted a systematic urban lifestyle, which tends to remove the political and traditional hierarchy factors from eating rituals and replaces it with popular and casual relations to food and eating consumption. The change of the family structure and living space of the young generation determines the new way they see food and cooking.

For example, one of the popular social media accounts on Weibo is "Eating Diary." The channel started in 2013 and has 17 million followers and teaches viewers how to cook quick comfort food or food specifically for young people that live alone or are in couples. All the videos feature a soft pale color palette, with soft background music, no vocals and warm light, in a specially designed kitchen where a cute cat lives. The cooking process in these videos is quiet, fast and independent, far different from the traditional image for Chinese cuisine, which is always busy, noisy and complicated. Even though the young generation might not have time to cook during their busy lives, this modern, fashionable way of cooking matches their fantasies about food and eating.

The boom of homogenized cooking videos full of embellishment, design and prettified foods continued for a couple of years until a further, new style of cooking videos went viral on social media. Chef Wang Gang is an iconic figure in this newly defined cooking video movement. In the Southern People Weekly Magazine's report (Bai Shan, 2019)[3], Wang was described as "a middle-school drop-out, an uprising social media star with only a Sony camera and a computer." He got into the field in a rather casual way by accident; he had no experience in filming and was simply a professional chef in a Sichuan cuisine restaurant. He shot his first video in March 2017 on how to cook eggplant in his real working kitchen and unexpectedly received more than 10 thousand clicks and 800 comments. The popularity of this video gave him another option and inspired his career as a creator of social media cooking tutorial videos. He has described his video style as "real stuff with no nonsense" and teaches practical cooking skills. He has been recognized on social media as a "hardcore chef" because he shows what a real (even crude) traditional Sichuan restaurant kitchen looks like and the entire process of cooking from the very beginning (raw 
meat or a live duck) to the prepared dish with no fancy presentation, no embellishment and no filters.

\section{EXPLORING THREE LEVELS OF "REAL" IN CHEF WANG'S VIDEOSTYLE PALETTE}

The popularity of Chef Wang Gang's cooking videos is not accidental. The phenomenon reflects the new social and cultural development that has driven a shift in the public's video preferences. Wang's videos appeared just as people got tired of watching years of homogenized "Instagrammed " cooking videos and wanted something more realistic to watch. In all of Wang's videos, he typically opens with simple words: "Today, I will show you how to cook..." and the ends with the "technical summary" listing the cooking steps, making the video more like a serious practical tutorial for cooking. All his videos are about 2-3 minutes, much shorter than most of other cooking videos, to meet his goal of "showing the audience the essence." Chef Wang Gang is from a small town in Sichuan, a southwest province in China. Sichuan cuisine is famous for its bold flavor and spiciness, having swept across China and become tremendously popular in recent years, especially among the younger generations (to some extent, similar to Indian food in Britain after World War II). According to the survey conducted jointly by Welloff Living Magazine and Tsinghua Media Lab, Sichuan cuisine became Chinese people's favorite cuisine in 2017, among all ten Great Cuisines of China (Well-off Living Magazine, 2017.)[4] Given the fact that spicy food triggers the brain to release endorphins - the body's natural pain reliever, the food critics argue one of the reasons for Sichuan cuisine's popularity is that the accelerated pace of modern life motivates people's preference for spicy and pungent food; these foods help relieve pressure and boost happiness. Chef Wang's local accent makes his videos seems more authentic. The real kitchen background, the real chef and the real cooking tips for Sichuan dishes are the outstanding points that win people over.

The continuing popularity of Wang's videos is not only related to changes in food taste and society's passion for Sichuan cuisine. His videos are considered a critical reaction to China's worship of luxury banquets among the upper class. Local elements in videos, including local flavor and accents, are no longer dismissed as outdated; they have merged with a new fashion chased by the younger generation, who deem this type of video "rustic" and "super cool." China's emerging nationalism, which has grown especially strong on social media, doubtless contributes to this general attitude change, similar to many countries that aspire to an identifiable and appealing cuisine using signature dishes as nation-building tools to generate civic pride (Catherine Henderson, 2014)[5].

The young generation's support for rustic videos is also an expression of nostalgic sentiment; "a rebellion against the modern idea of time, the time of history and progress" (Khoo, 2013)[6]. Imagine a young person left his or her small hometown and moved to a city. Life changes, but the childhood memories of feelings and tastes remain. Even if China's rapid urbanization process has destroyed the locations they remember, these "rustic videos" help people recall their childhood. The place in the video may not be their actual hometown, but it calls to mind "the hometown that one can never go back to." In Wang's case, lots of comments on his videos mention that his real, homemade food made them (the commenters) think of their mother/grandmother or that the big pot Wang used is like what they had in their families when they were kids. Cultural and sentimental motivations result in people seeking more relevant content, and social media companies have seen this new direction as an opportunity to further promote such video channels for profit. As "people's cultural tactics were turned into strategies now sold to them" (Manovich, 2009)[7], the result of the interaction between social media users preferences and the creation of related content is that social media is actually empowering the voice of people from grassroots movements - Chef Wang Gang is such an example, and the public increasingly enjoys these "cool rustic videos."

However, Chef Wang Gang recently provoked a huge controversy after posting two tutorial videos about how to cook braised salamander and rabbit dishes. In one video, in his usual way, he holds the live salamander before the camera and shows how to kill, wash and prepare it for cooking. After widespread criticism, he apologized and explained that the salamander was not a protected wild animal but a type that is legally farmed for food in China; however, the video still caused backlash. People stated that the content was cruel and that Wang has no respect for life and no love for food. Wang defended himself, saying that killing is a part of his daily work as a chef; "You can't tell me that the pork you eat comes from a pig who committed suicide and divided itself up into chunks of meat." His supporters also commented that the videos just show the entire process of cooking and remind people of their real connections with food.

The controversy surrounding Wang Gang's videos, on some level, tests people's boundaries of what "real" food/cooking is; some are happy to see a rustic kitchen/kitchenware and authentic dishes; for some, the whole process from raw meat to finished dishes is exactly what they want to see from Wang's videos. Still 
others are interested in seeing how a live animal is treated and cooked-their comments are basically "that is super hardcore!"

\section{EVERYDAY CULTURAL POLITICS BEYOND THE COOKING VIDEOS}

The development of food culture and industry can provide clues as to why these various levels of "the real" appear. China's food industry has adjusted to the general trend of modernization (Tian et al., 2018) as it relates to the development of food shopping. Before the reform and opening-up policy of 1978, people could only get food through a quota system and use coupons for food distribution from government agencies due to an insufficient food supply. Thus, supplying enough food to people was the top priority in food culture and influenced the way food was produced. For example, in the event of a disaster in the $1960 \mathrm{~s}$, people tried to develop all sorts of wild vegetables and weeds for survival, which gave many Westerners the illusion that the Chinese dare to eat all edible items (Tian et al., 2018). After the 1980s, with the transformation to a market economy, farmers' markets became popular in urban and suburban areas, where farmers took their homegrown vegetables, poultry and meat to the market for profit. Considering that many Chinese dishes emphasize the freshness of raw material, it is widely accepted in Chinese food culture that fresh-cut meat is the best. Therefore, people tended to go to farmers' markets every day to get fresh food and cooking materials, and the markets were important hubs of social activity.

Starting in the late 1990s, with the increasing presence of supermarkets in Chinese cities and towns, manufactured food came to people's lives. Cut and nicely packed food and meat are sold in supermarkets; labels on food products have replaced verbal information from farmers, and food shopping behavior has evolved into a reflection of the modern, convenience-centered urban civilization. However, this modernization process is unbalanced in some areas. The sophisticated supermarket chain system and new options for food choices emerged much earlier in big cities than in small ones, while farmers' markets are still more popular in rural areas than in big towns. After the SARS epidemic in China in 2003, the government gradually banned the live poultry market in major cities, including Beijing, Shanghai and Guangdong. Residents in these cities who used to watch as live poultry was killed and treated for cooking to demonstrate its freshness after purchase, which was quite common in previous famers markets, could no longer see this method any more.

In 2012, the new retail industry developed as China's largest retailers entered the online food market sphere. People started enjoying a new way of shopping for food, wherein they buy meat, vegetables or other food materials by clicking on mobile apps, and then they receive them within one hour. According to Yiguan Analysys' report, the scale of the online market for fresh food in China reached 1790 billion RMB (Yiguan Analysis, 2018)[8]. The food images on the online market are identical and standardized, and people do not need to look for and pick the food they want on the rack but only need to search for keywords and add the items to their shopping cart. The target population for the online fresh market is urban office workers who do not have time or do not like to shop in supermarkets or farmers markets.

The transition of food consumption sites from government agencies and farmers markets to supermarkets and online fresh food markets reflects the development of the food retail industry. More importantly, it impacts how people consume food and further impacts people's attitudes toward food. Because all these changes cannot occur simultaneously in all places, people of different ages or growing up in various areas might have different experiences and memories regarding food and cooking. When the controversy about Chef Wang's videos moved from online to offline, these differences on larger populations showed more clearly. Old generations that preserve the traditional Chinese cooking culture argue that the meat and vegetables in supermarkets and online markets are not fresh, and they prefer farmers markets for food consumption, whereas young generations are more likely to get their food in supermarkets or online markets, as it is packed nicely and the shopping is less time-consuming. People located far from cities and towns have less opportunity to buy manufactured food; thus, killing poultry for food is still part of their cooking habits. However, many people are transitioning from eating well to eating more rationally by considering nutrition, functions, economy and civilization (Tian et al., 2018).

In this respect, the controversy toward Wang's video is due to people's conflicting lifestyles. People who still participate in or experience the farmers market system are more likely to accept the process that Chef Wang presents to his audience, from killing to cooking. People who are used to online food markets may love the rustic kitchen shown in Chef Wang's videos but may not accept how the animals are killed for cooking; this act is too far from their way of life as they better adapt to the "clean" food images provided by the fresh market mobile apps.

Rather than the one-sided impact of social and cultural development on cooking video preferences, the meta-process of food/cooking (mediafication of food) also constitutes the society. The most famous food video genre is Mukbang, which is a live-stream show 
originally from South Korea that invites viewers to watch a person eat a tremendous amount of food and to send online gifts (to the person). Some attribute the popularity of Mukbang videos in Asia to the rise of single-person households and the erosion of traditional communal meals. Lonely, homesick viewers might now set a plate in front of their screens and pretend to eat in company (Orange, 2017)[9]. Kyung Kim, the professor of East Asian studies at the University of California, Irvine, thinks the audience hunger for Mukbang is a yearning for something besides connection - It's a desire for something real: "If you think about K-pop or Kdrama - they're very artificial. They're all about makeup and plastic surgeries. Mukbang - to be exactly opposite of all of the things right now Korean popular culture really stands for." (2015 National Public Radio, 2015)[10]

Similar to Mukbang, cooking videos in China influence people's ideas about food and serve as emotional comfort. People comment that they feel relaxed after watching Wang's videos, even if they don't learn any cooking tips. The followers of Chef Wang's self-organized fan group have a nickname Gangsiqiu ("a dish washing tool"). They comment, chat and tell funny stories about Wang's cooking videos within the group. To some extent, Wang's videos have become a small social network platform for people interested in (watching) cooking. Also, because of the trend in Yangsheng, which refers to health cultivation, many Chinese advocate for less oil and salt in Chinese cuisine and a large number of young people tend to stay fit and avoid eating heavy foods. From a psychological angle, watching Chef Wang's cooking videos, where the dishes' flavors are always heavy and strong, functions as a psychological compensation for viewers who hope for exciting food from the heart but in reality, have to choose mild healthy food. "Tell me what you eat, and I will tell you who you are" (Stringfellow et al., 2013) no longer applies to today's contexts, and the phrase might be changed to "tell me what food you watch, and I will tell you who you are."

\section{CONCLUSION}

Wang Gang has been an iconic figure during the digitization of Chinese cooking. The paper examines the factors that led to Wang's popularity on Chinese social media in recent years. The audience's food video preferences, from beautiful cooking women to glorification of the food and a rustic and real style, reflects a critique of the Chinese culture of luxury banquets and the rise of grassroots culture. In addition, the food industry's development and changes to food culture have made different groups of people grow apart with conflicting lifestyles, which has triggered controversy surrounding Wang Gang's cooking videos. Besides discussing the specific cultural politics that influence cooking videos, this paper also explores why and how food media serve as a source of emotional comfort.

\section{REFERENCES}

[1] Stringfellow, L., MacLaren, A., Maclean, M., \& O' Gorman, K. Conceptualizing taste: Food, culture and celebrities. Tourism Management, 37, (2013), $77 \quad-\quad 85 . \quad$ DOI: https://doi.org/10.1016/j.tourman.2012.12.016H.

[2] Tian, R. G., Tian, K., Dandan, Z., \& Wang, C. H. Food Culture in China: From Social Political Perspectives. Trames : A Journal of the Humanities and Social Sciences; Tallinn, 22(4), (2018), 345364.

[3] Bai Shan: Wang Gang, a food blogger's unexpected success, 2019, March 26. The Southern People Weekly Magazine. Retrieved from http://www.nfpeople.com/article/9075.

[4] Well-off Living Magazine. (2017, October 25). 2017 Chinese Food Index. Retrieved from http://www.cxxkw.org/NewsView.asp?/803.html

[5] Catherine Henderson, J. Food and culture: in search of a Singapore cuisine. British Food Journal, 116(6), (2014), 904 - 917. DOI: https://doi.org/10.1108/BFJ-12-2012-0291

[6] Khoo, G. C. Where the Heart Is: Cinema and Civic Life in Singapore, 2013. Retrieved from https://openresearchrepository.anu.edu.au/handle/1885/63188

[7] Manovich, L. The Practice of Everyday (Media) Life: From Mass Consumption to Mass Cultural Production? Critical Inquiry, 35(2), (2009), 319331. DOI: https://doi.org/10.1086/596645

[8] Yiguan Analysis. (2018). Annual comprehensive analysis of China's fresh e-commerce industry.Yiguan Analysis. Retrieved from https://www.analysys.cn/article/analysis/detail/100 1196

[9] Orange, M. Screening the World: Entertainment Unboxed. Virginia Quarterly Review, 93(3), (2017), s182-185.

[10] Koreans Have An Insatiable Appetite For Watching Strangers Binge Eat. National Public Radio, Morning Edition; Washington, D.C. 2015. Retrieved from http://search.proquest.com/docview/1667635221/ci tation/A1CAF6954A0D4D0BPQ/1 